\title{
Comparison of voluntary ethanol intake by two pairs of rat lines used as genetic models of anxiety
}

G.E. Da Silva ${ }^{1}$,

A. Ramos ${ }^{2}$ and

R.N. Takahashi ${ }^{3}$

\author{
${ }^{1}$ Departamento de Ciências Farmacêuticas, Universidade Regional de Blumenau, \\ FURB, Blumenau, SC, Brasil \\ Departamentos de ${ }^{2}$ Biologia Celular, Embriologia e Genética, and ${ }^{3}$ Farmacologia, \\ Centro de Ciências Biológicas, Universidade Federal de Santa Catarina, \\ Florianópolis, SC, Brasil
}

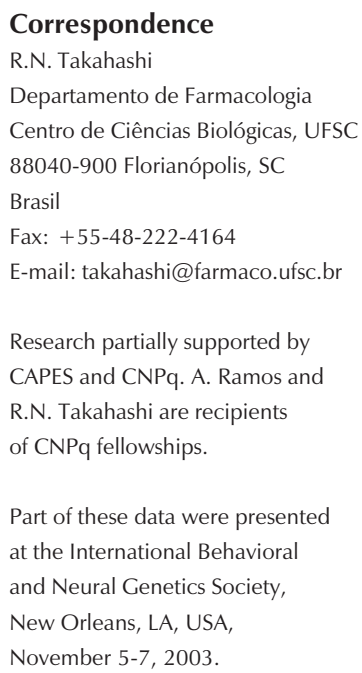

Received November 28, 2003 Accepted July 6, 2004

\begin{abstract}
The relationship between anxiety-related behaviors and voluntary ethanol intake was examined in two pairs of rat lines by the oral ethanol self-administration procedure. Floripa high $(\mathrm{H})$ and low (L) rats selectively bred for contrasting anxiety responses in the open-field test, and two inbred strains, spontaneously hypertensive rats (SHR) and Lewis rats which are known to differ significantly when submitted to several behavioral tests of anxiety/emotionality, were used (9-10 animals/line/sex). No differences in the choice of ethanol solutions ( $2 \%$, days $1-4$, and $4 \%$, days 5-8, respectively) in a 2-bottle paradigm were detected between Floripa $\mathrm{H}$ and L rats $(1.94 \pm 0.37$ vs $1.61 \pm 0.37$ $\mathrm{g} / \mathrm{kg}$ for ethanol intake on day 8 by the Floripa $\mathrm{H}$ and $\mathrm{L}$ rat lines, respectively). Contrary to expectations, the less anxious SHR rats consumed significantly more ethanol than Lewis rats (respective intake of $2.30 \pm 0.45$ and $0.72 \pm 0.33 \mathrm{~g} / \mathrm{kg}$ on day 8 ) which are known to be both addiction-prone and highly anxious. Regardless of strain, female rats consumed more ethanol than males (approximately 46\%). The results showed no relationship between high anxiety and voluntary intake of ethanol for Floripa $\mathrm{H}$ and $\mathrm{L}$ rats. A negative association between these two variables, however, was found for SHR and Lewis rat strains. Data from the literature regarding the association between anxiety and alcohol intake in animal models are not conclusive, but the present results indicate that factors other than increased inborn anxiety probably lead to the individual differences in ethanol drinking behavior.
\end{abstract}

Key words

- Anxiety

- Ethanol intake

- Spontaneously hypertensive rats

- Lewis

- Selected lines

- Inbred strains

\section{Introduction}

A variety of evidence has associated increased ethanol consumption and anxietyrelated behavior. For example, the tensionreduction hypothesis predicts that individuals who are innately anxious or stressed while in a non-drugged state are more sensitive to the anxiolytic effects of ethanol, and therefore show a higher predisposition to ethanol drinking (1). Whereas clinical studies demonstrate this correlation, there is some evidence that chronic alcohol abuse precedes anxiety and anxiety disorders, and not vice versa (2). The literature about the relationship between anxiety and ethanol intake in 
animal models is quite limited. Spanagel et al. (3) reported that anxiety levels were positively correlated with alcohol consumption in Wistar rats selected from a heterogeneous group for individual differences in anxietyrelated behavior on the elevated plus maze, suggesting a link between emotionality and alcohol consumption. This was confirmed in our laboratory using the conditioned place preference paradigm (4), since a significant place preference for the ethanol-paired compartment was shown by rats previously selected for anxiety. Also, in this context Möller et al. (5) showed that bilateral lesions of the central amygdala, an important region for anxiety-related behavior (6), reduced both experimental anxiety and voluntary ethanol intake. In addition, inverse strategies have also been applied, with rats selectively bred for high ethanol consumption being evaluated for their anxiety behavior. Steward et al. (7) found that genetically selected alcoholpreferring rats showed a greater innate degree of anxiety than alcohol-non-preferring rats. Later, Colombo et al. (8) found similar results using Sardinian alcohol-preferring and non-preferring rats.

Despite these positive findings, other studies did not find such a correlation. A study using alcohol-accepting and alcohol-avoiding rats showed that these lines did not differ in their anxiety profile (9). Viglinskaya et al. (10) compared several different strains of alcohol drinking and non-drinking rats in tests of anxiety and immobility and concluded that there was no correlation between alcohol consumption and measures of anxiety. An extensive study using 13 behavioral measures in alcohol-preferring and non-preferring rat lines provided mixed support for a link between alcohol drinking and emotionality or anxiety (11). Recently, a study by Fernández-Teruel et al. (12) indicated that apparently there is no direct relationship between trait anxiety, which is higher in Roman low-avoidance rats compared to Roman high-avoidance rats, and alcohol con- sumption. In addition, Henniger et al. (13), using rats bred and selected for differences in anxiety-related behavior on the elevated plus maze, also showed no relationship between anxiety and ethanol consumption.

The aim of the present study was to determine if rats that differ genetically in anxietyrelated behaviors also differ in the acquisition of ethanol intake. In the first part of the study, Floripa $\mathrm{H}$ and $\mathrm{L}$ rat lines, two directionally selected for 4 generations for high and low scores of central locomotion in the open field, respectively (14), were tested in the paradigm of ethanol self administration. In a second part of the study, spontaneously hypertensive rats (SHR) and Lewis inbred strains that are genetically contrasting regarding anxiety responses (15-17) were also tested in the same ethanol consumption paradigm.

\section{Material and Methods}

\section{Animals}

Male and female rats (12-13 weeks old) of the inbred SHR and Lewis strains and of the outbred Floripa $\mathrm{H}$ and $\mathrm{L}$ lines were used. SHR and Lewis rats were obtained from colonies bred in our laboratory under a system of brother-sister mating. Breeding and selection of the Floripa $\mathrm{H}$ and $\mathrm{L}$ rats were described previously (14). Briefly, genetically heterogeneous animals (obtained through the intercross of three rat strains, Wistar, Hooded and Lewis) were submitted to the open-field, elevated plus-maze and black/white box tests. Animals with high and low scores for central locomotion in the open field were then mated to establish the new $\mathrm{H}$ and $\mathrm{L}$ lines, respectively. At each generation, the offspring from the two breeding lines was tested in the open field and the best high- and low-score animals were selected for breeding within the $\mathrm{H}$ and $\mathrm{L}$ lines, respectively. All animals weighing approximately 250-300 g were housed individually 
in hanging iron cages at constant temperature $\left(22 \pm 1^{\circ} \mathrm{C}\right)$ on a 12 -h day/night cycle (lights off at 7:00 pm) with food and water available ad libitum. All procedures used in the present study were in strict accordance with the guidelines of the UFSC University Animal Care Committee (CEUA-UFSC).

\section{Ethanol self-administration procedure}

A standardized testing procedure for ethanol preference was used as described by Spanagel et al. (3), in which two bottles of either ethanol solution or water were made available continuously as a free choice to the animals. The 24-h consumption of ethanol or water was measured daily at 11:00 am. Body weight was recorded every third day. The position of the bottle was changed daily. The concentration of the ethanol solution was increased after 4 days as follows: day 14: $2 \%$; day 5-8: $4 \%$ (v/v).

\section{Statistical analysis}

Data were analyzed statistically by threeway analysis of variance (ANOVA) for repeated measures, with the level of significance set at $\mathrm{P}<0.05$. When a main factor was found to be significant, post hoc comparisons were performed using the Newman-Keuls test.

\section{Results}

At the beginning of the experiment, male and female Floripa $\mathrm{H}$ rats weighed $314.5 \pm$ 14.0 and $218.2 \pm 5.9 \mathrm{~g}$ while male and female Floripa $L$ rats weighed $313.6 \pm 10.8$ and $220 \pm 7.3 \mathrm{~g}$, respectively; male and female SHR weighed $313.5 \pm 4.5$ and 190.4 $\pm 3.4 \mathrm{~g}$ and male and female Lewis rats weighed $315.3 \pm 11.92$ and $203.6 \pm 4.2 \mathrm{~g}$, respectively. At the end of the experiment after 8 days, male and female Floripa $\mathrm{H}$ rats weighed $327.3 \pm 13.5$ and $220.4 \pm 4.9 \mathrm{~g}$ while male and female Floripa L rats weighed
$325.6 \pm 9.8$ and $229.3 \pm 6.5 \mathrm{~g}$, respectively. Male and female SHR weighed 326.6 \pm 5.1 and $197.8 \pm 3.5 \mathrm{~g}$, while male and female Lewis rats weighed $325.2 \pm 12.8$ and $209.0 \pm$ $4.6 \mathrm{~g}$, respectively. ANOVA showed no significant differences in this measure.

Figure 1A shows ethanol intake reported as $\mathrm{g} \mathrm{kg}^{-1}$ day $^{-1}$ for male and female Floripa $\mathrm{H}$

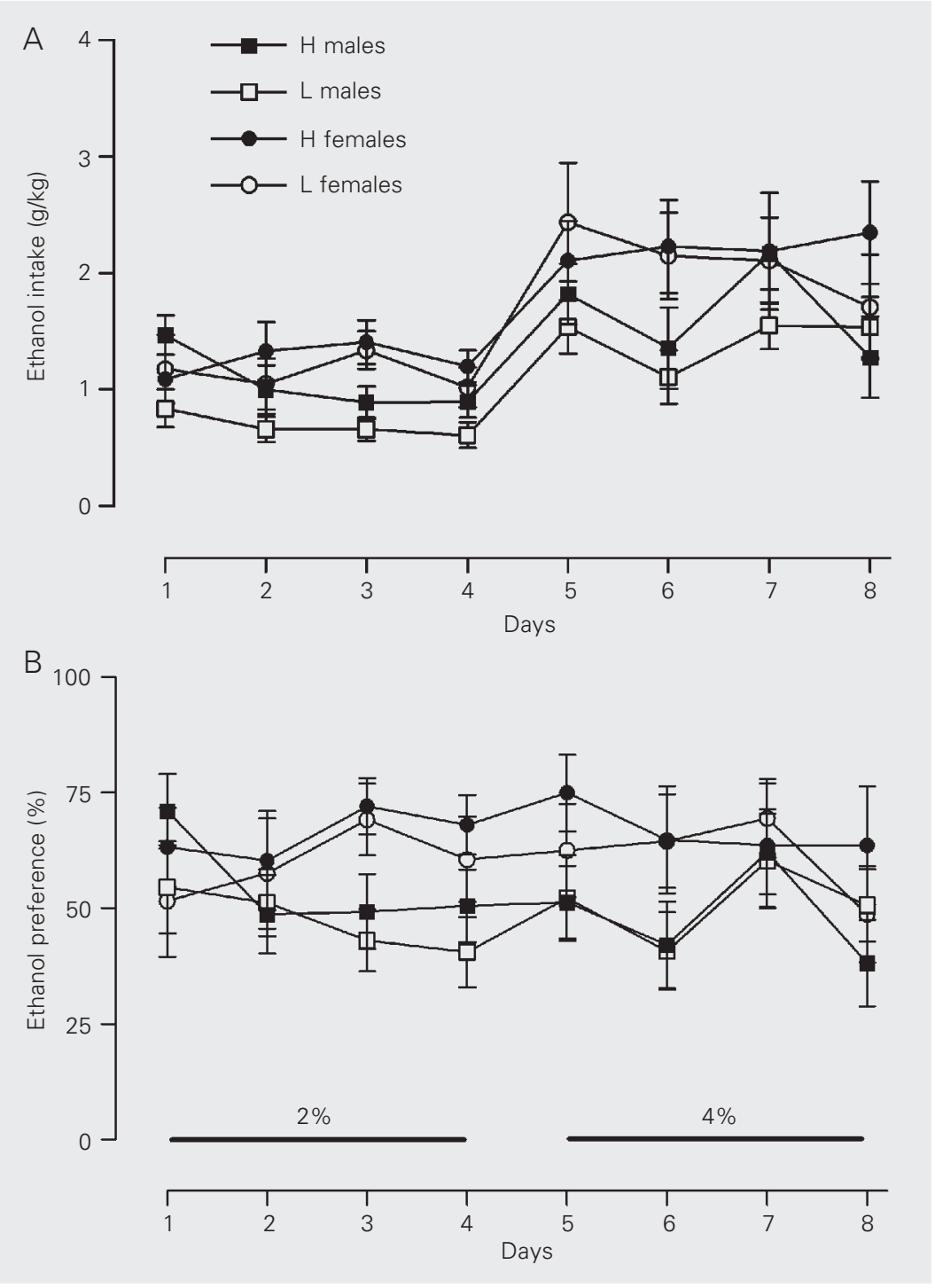

Figure 1. Comparison of ethanol intake (A) and ethanol preference (B) between Floripa high $(\mathrm{H})$ and low $(\mathrm{L})$ lines. The concentration of the ethanol drinking solution was increased from 2 to $4 \%$. Data are reported as $\mathrm{g}$ absolute ethanol ingested daily per $\mathrm{kg}$ body weight in panel $A$ and as percent of ethanol compared to total fluid intake in panel $B$. Each point indicates the mean \pm SEM for 9-10 animals per group. No strain effect was detected but females showed a greater ethanol intake and preference than males $(P<0.05$, ANOVA). 
and $\mathrm{L}$ rats exposed to two ethanol concentrations. Analysis of oral ethanol self-administration over a period of 8 days revealed a significant effect of gender $(\mathrm{F}(1,37)=6.48$, $\mathrm{P}<0.01)$, with females drinking substantially more alcohol than males, and day $(\mathrm{F}$
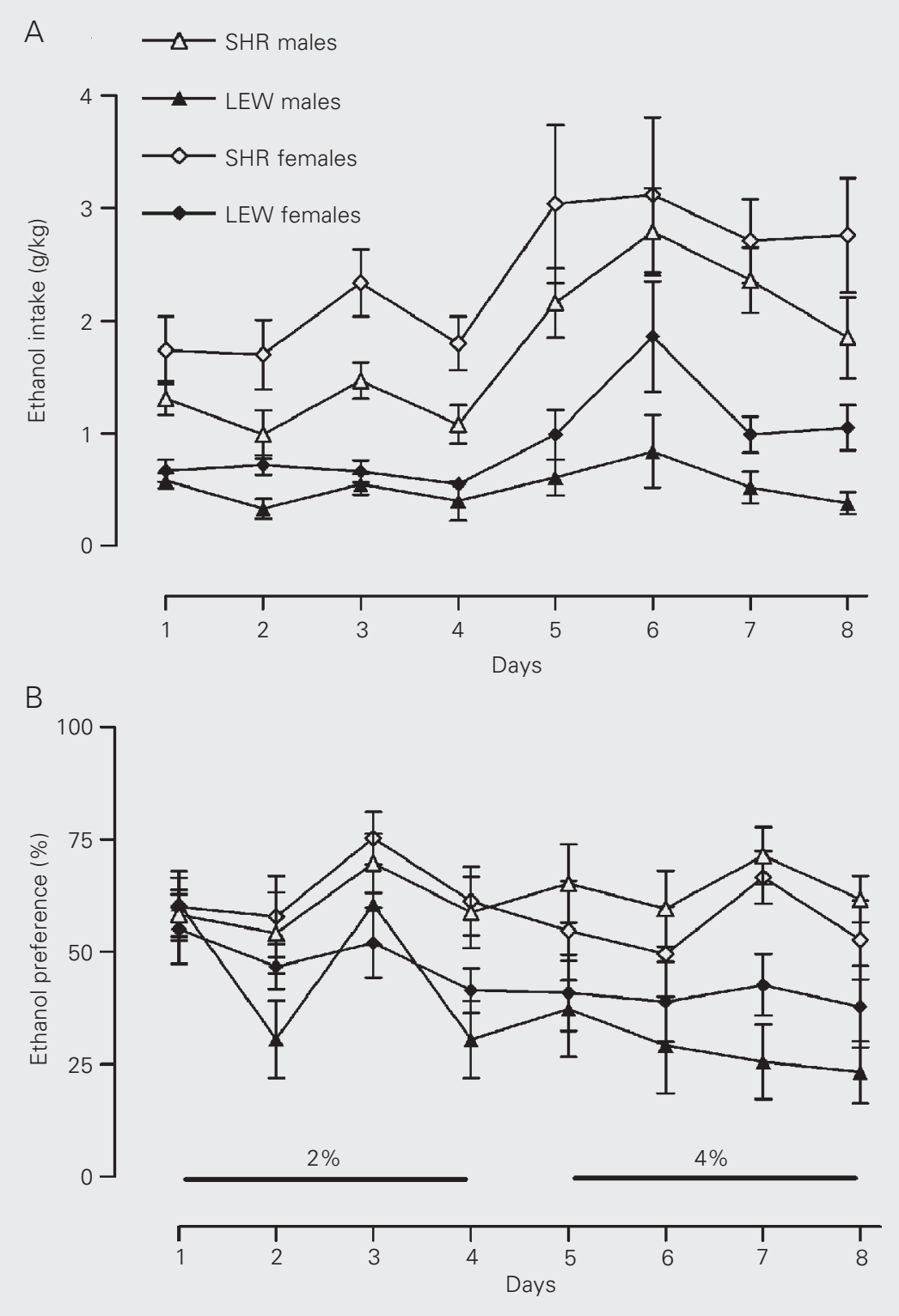

Figure 2. Comparison of ethanol intake (A) and ethanol preference (B) between spontaneously hypertensive rats (SHR) and Lewis (LEW) rats. The concentration of the ethanol drinking solution was increased from 2 to $4 \%$. Data are reported as $\mathrm{g}$ absolute ethanol ingested daily per $\mathrm{kg}$ body weight in panel $A$ and as percent of ethanol compared to total fluid intake in panel $B$. Each point indicates the mean \pm SEM of 9-10 animals per group. SHR showed a greater ethanol intake and preference than LEW rats and female rats consumed more ethanol than male rats $(P<0.05$, ANOVA).
$(7,259)=15.60, \mathrm{P}<0.00001)$ because ethanol concentration increased after the 4 th day. No main effect of strain was found $(\mathrm{F}(1,37)$ $=1.231, \mathrm{P}=0.27)$. Also, no significant interactions were found between gender and day $(\mathrm{F}(7,259)=1.61, \mathrm{P}=0.130)$ or strain and day $(\mathrm{F}(7,259)=0.263, \mathrm{P}=0.96)$.

ANOVA for ethanol preference (Figure 1B) also revealed a significant effect of gen$\operatorname{der}(\mathrm{F}(1,37)=4.87, \mathrm{P}=0.0335)$, with females showing more preference than males. No main effect was found for strain or day $(\mathrm{F}$ $(1,37)=0.49, \mathrm{P}=0.48$, and $\mathrm{F}(7,259)=1.32$, $\mathrm{P}=0.23$, respectively). No interaction was found between strain and day $(\mathrm{F}(7,259)=$ $0.46, \mathrm{P}=0.86$ ).

Figure 2A shows the ethanol intake by male and female SHR and Lewis rats. ANOVA of these data showed a significant effect of gender $(\mathrm{F}(1,36)=11.91, \mathrm{P}<0.001)$, with female SHR and Lewis rats consuming more ethanol than males, and of day factor $(\mathrm{F}(7,252)=9.27, \mathrm{P}<0.00001)$, possibly related to the change in ethanol concentration. A main strain effect was significant for ethanol consumption $(\mathrm{F}(1,36)=76.62, \mathrm{P}<$ 0.00001), with SHR consuming more ethanol than Lewis rats. ANOVA also revealed a significant day $v s$ strain interaction $(\mathrm{F}(7,252)$ $=2.09, \mathrm{P}=0.04)$.

ANOVA for ethanol preference (Figure 2B) did not show a significant effect of gender $(F(1,36)=0.41, P=0.52)$. Nevertheless, ANOVA revealed a significant difference between strains in ethanol preference $(\mathrm{F}(1,36)=31.65, \mathrm{P}<0.00001)$, with SHR displaying a greater preference for ethanol than Lewis rats, and also an effect of day ( $F$ $(7,252)=3.43, \mathrm{P}<0.001)$. No significant effects were found for the strain $v s$ day interaction $(\mathrm{F}(7,252)=1.59, \mathrm{P}=0.13)$.

\section{Discussion}

In the present study, we compared two pairs of rat strains - previously known to show contrasting anxiety-related responses 
in a series of paradigms (14-17) - in an oral ethanol self-administration procedure. The expected relationship between the initiation of ethanol intake and the known levels of innate anxiety was not found. No differences in ethanol intake behavior were found between the Floripa $\mathrm{H}$ and $\mathrm{L}$ rat lines genetically selected for low and high emotionality, respectively. Moreover, contrary to what was expected, SHR consumed more ethanol than Lewis rats, a strain known to present more anxiety-like behaviors than their SHR counterparts of both sexes $(16,17)$. In addition, confirming other studies, female rats displayed a higher ethanol drinking pattern than male rats (18-21) regardless of strain. Although at variance with the study of Spanagel et al. (3), which reported that "anxious" rats consumed significantly more ethanol than "non-anxious" rats selected on the elevated plus-maze test, the present results confirm and extend recent findings suggesting that increased levels of inborn anxiety and high alcohol consumption are not necessarily related $(12,13)$.

It is important to emphasize that in the present study the association between anxiety levels and ethanol preference was examined in two distinct pairs of rat lines genetically displaying contrasting anxiety responses, namely the Floripa $\mathrm{H}$ and $\mathrm{L}$ rats and the Lewis and SHR rats. The Floripa $\mathrm{H}$ and $\mathrm{L}$ lines were selected over 4 generations for high and low scores of central locomotion in the open field. As a result, throughout generations these lines developed differences not only regarding the selected behavior but also regarding other anxiety-related measures tested on the elevated plus maze and the black/white box (14). In all cases, Floripa $\mathrm{H}$ rats displayed higher levels of approach towards the aversive environments of each test. Although in a less marked manner, rats of the 4th generation of selection also showed moderate differences in peripheral locomotion in the open field, a measure thought to reflect general locomotor activity (14). More recent experiments, however, have indicated that such differences tend to disappear in further generations (Ramos A, unpublished data).

When the animals were exposed for the first time to the oral ethanol self-administration procedure, there was no significant difference in ethanol intake between Floripa $\mathrm{H}$ and $\mathrm{L}$ rat lines. As mentioned before, these findings are in agreement with the study by Henniger et al. (13), which also used rat lines selectively bred for differences in anxiety responses, although there are some methodological differences between the two studies: in our study the rats had a choice between water and low concentrations of ethanol solutions ( 2 and $4 \%$, respectively) in a 2bottle paradigm, while in the study of Henniger et al. (13), rats had a choice between water and higher ethanol concentrations $(5,10$ and $20 \%$, respectively) in a $4-$ bottle paradigm from the beginning to the end. Although we did not measure blood ethanol levels, it should be pointed out that rats usually prefer alcohol solutions of lower rather than higher concentrations (i.e., $>6 \%$ (v/v) ethanol solutions), probably due to taste aversion. Furthermore, in the study by Henniger et al. (13), the high anxiety behavior and low anxiety behavior lines were selected in the elevated plus-maze test. Thus, it is important to note that the elevated plusmaze and the open-field tests are likely to assess different forms of anxiety $(22,23)$. In a recent review, Prut and Belzung (24) concluded that the open-field test may be an animal model of non-pathological anxiety, sensitive to anxiolytic-like effects of classical benzodiazepine and 5-HT1 receptor agonists but not to the effects of compounds displaying anxiolytic-like effects regarding the clinical entity termed "anxiety disorders".

The relationship between high anxiety and high ethanol intake was not confirmed in the present study using the inbred strains SHR and Lewis. However, a negative association was found, contrary to the aforemen- 
tioned tension-reduction hypothesis, with the less anxious SHR consuming more alcohol than the more anxious Lewis rats. Recent studies have shown that these strains constitute a useful genetic model for the study of anxiety, with Lewis rats consistently displaying more anxiety-like behaviors in the open field, the elevated plus maze and the black/white box, three tests of emotionality/ anxiety, than their SHR counterparts of both sexes $(16,17)$. Interestingly, the two strains do not differ in any measure of general locomotion in the open field and the elevated plus maze (17). Besides, Lewis rats are routinely used in drug research and are considered to be genetically predisposed to discriminate positive reinforcement of different classes of drugs such as cocaine (25), morphine (26) and ethanol (27). Therefore, it was surprising to find here that the SHR strain showed higher voluntary intake of ethanol than the Lewis strain. It is known that SHR are more sensitive to the hypnotic effects of ethanol and consume more ethanol than the normotensive Wistar-Kyoto rats (28). This is consistent with the data reported by Wood et al. (29), which show that genetically hypertensive mice drink more ethanol than normotensive mice. However, recent findings by Cailhol and Mormède (20) using a continuous free access procedure have shown that, after progressive initiation to ethanol, SHR drink less alcohol than Wistar Kyoto hyperactive rats. The strain difference in ethanol drinking behavior found in the present study may be due to taste aversion, since other studies have shown that strains with higher preference for sweet and/or bitter solutions also tend to display higher consumption of ethanol $(30,31)$. Further experiments comparing saccharin and quinine pref- erence in SHR and Lewis rats are being carried out in our laboratory in order to clarify this issue.

Certainly, conflicting results among studies on ethanol self-administration might be partly explained by methodological, species and/or strain differences. The interaction between different rat lines and behavioral measures was elegantly analyzed by Overstreet et al. (11). These investigators confirmed that there are behavioral differences between several alcohol-preferring and nonpreferring rat lines/strains, with the former animals exhibiting less anxiogenic behavior than the latter, in direct contrast with earlier suggestions comparing just one pair of rat lines. Indeed, alcohol abuse and anxiety constitute a complex phenotype that is shaped by environmental and genetic factors and by an intricate interaction of these factors.

The important finding in the present study, however, is that our data, considered as a whole, fail to support the hypothesis that high ethanol intake is closely related to an inborn increased anxiety-related behavior of the animals, independent of genetic background. These data support and extend the interpretation put forward by Henniger et al. (13), that these factors might not necessarily be co-selected when animals are selectively bred either for differences in emotionality or for differences in ethanol preference. In this context, it is important to mention that findings from the National Comorbidity Survey (32) did not demonstrate a significant correlation between anxiety disorders and alcohol use disorders. Thus, the present results provide evidence for the lack of a high/general correlation between anxiety and voluntary ethanol intake in laboratory animals. 


\section{References}

1. Cappell H \& Herman CP (1972). Alcohol and tension reduction: a review. Quarterly Journal of Studies on Alcohol, 33: 33-64.

2. Allan CA (1995). Alcohol problems and anxiety disorders - a critical review. Alcohol and Alcoholism, 30: 145-151.

3. Spanagel R, Montkowski A, Allingham K, Stöhr T, Shoaib M, Holsboer F \& Landgraf R (1995). Anxiety: a potential predictor of vulnerability to the initiation of ethanol self-administration in rats. Psychopharmacology, 122: 369-373.

4. Blatt SL \& Takahashi RN (1999). Experimental anxiety and the reinforcing effects of ethanol in rats. Brazilian Journal of Medical and Biological Research, 32: 457-461.

5. Möller C, Wiklund L, Sommer W, Thorsell A \& Heilig M (1997). Decreased experimental anxiety and voluntary ethanol consumption in rats following central but not basolateral amygdala lesions. Brain Research, 760: 94-101.

6. Davis M, Rainnie D \& Cassell M (1994). Neurotransmission in the rat amygdala related to fear and anxiety. Trends in Neurosciences, 17: $208-214$

7. Stewart RB, Gatto GJ, Lumeng L, Li TK \& Murphy JM (1993). Comparison of alcohol-preferring (P) and non-preferring (NP) rats on tests of anxiety and for the anxiolytic effects of ethanol. Alcohol, 10: 1-10.

8. Colombo G, Agabio R, Lobina C, Reali L, Zocchi A, Fadda F \& Gessa GL (1995). Sardinian alcohol-preferring rats: a genetic animal model of anxiety. Physiology and Behavior, 57: 1181-1185.

9. Tuominen K, Hilakivi LA, Paivarinta P \& Korpi ER (1990). Behavior of alcohol-preferring AA and alcohol-avoiding ANA rat lines in tests of anxiety and aggression. Alcohol, 7: 349-353.

10. Viglinskaya IV, Overstreet DH, Kashevskaya OP, Badishtov BA, Kampov-Polevoy AB, Seredenin SB \& Halikas JA (1995). To drink or not to drink: tests of anxiety and immobility in alcohol-preferring and alcohol-non-preferring rat strains. Physiology and Behavior, 57: 937941.

11. Overstreet DH, Halikas JA, Seredenin SB et al. (1997). Behavioral similarities and differences among alcohol-preferring and -non-preferring rats: confirmation by factor analysis and extension to additional groups. Alcoholism, Clinical and Experimental Research, 21: 840-848.

12. Fernández-Teruel A, Driscoll P, Gil L, Aguilar R, Tobeña A \& Escorihuela RM (2002). Enduring effects of environmental enrichment on novelty seeking, saccharin and ethanol intake in two rat lines ( $\mathrm{RHA}$ / Verh and RLANerh) differing in incentive-seeking behavior. Pharmacology, Biochemistry, and Behavior, 73: 225-231.

13. Henniger MSH, Spanagel R, Wigger A, Landgraf $R$ \& Hölter SM (2002). Alcohol self-administration in two rat lines selectively bred for extremes in anxiety-related behavior. Neuropsychopharmacology, 26: 729-736.

14. Ramos A, Correia EC, Izídio GS \& Brüske GR (2003). Genetic selection of two new rat lines displaying different levels of anxietyrelated behaviors. Behavior Genetics, 33: 657-668.

15. Berton O, Aguerre S, Sarrieau A, Mormede P \& Chaouloff F (1998). Differential effects of social stress on central serotonergic activity and emotional reactivity in Lewis and spontaneously hypertensive rats. Neuroscience, 82: 147-159.

16. Ramos A, Berton O, Mormede P \& Chaouloff F (1997). A multiple- test study of anxiety-related behaviors in six inbred rat strains. Behavioural Brain Research, 85: 57-69.

17. Ramos A, Kangerski AL, Basso PF, Santos JES, Assreuy J, Vendruscolo LF \& Takahashi RN (2002). Evaluation of Lewis and SHR rat strains as a genetic model for the study of anxiety and pain. Behavioural Brain Research, 129: 113-123.

18. Almeida OFX, Shoaib M, Deike J, Fischer D, Darwish MH \& Patchev VK (1998). Gender differences in ethanol preference and ingestion in rats. Journal of Clinical Investigation, 101: 2677-2685.

19. Cailhol S \& Mormède $P$ (2001). Sex and strain differences in ethanol drinking: effects of gonadectomy. Alcoholism, Clinical Experimental Research, 25: 594-599.

20. Cailhol S \& Mormède $P$ (2002). Conditioned taste aversion and alcohol drinking: strain and gender differences. Journal of Studies on Alcohol, 63: 91-99.

21. Lancaster FE \& Spiegel KS (1992). Sex differences in pattern of drinking. Alcohol, 9: 415-420.

22. File SE, Zangrossi H, Sanders FL \& Mabbutt OS (1994). Raised corticosterone in the rat after exposure to the elevated plus-maze. Psychopharmacology, 113: 543-546.

23. Handley SE \& McBlane JW (1993). An assessment of the elevated X-maze for studying anxiety and anxiety-modulating drugs. Journal of Pharmacological and Toxicological Methods, 29: 129-138.

24. Prut $L$ \& Belzung $C$ (2003). The open field as a paradigm to measure the effects of drugs on anxiety like-behaviors: a review. European Journal of Pharmacology, 463: 3-33.

25. Kosten TA, Miserendino MJD, Chi S \& Nestler EJ (1994). Fischer and Lewis rat strains show differential cocaine effects in conditioned place preference and behavioral sensitization but not in locomotor activity or conditioned taste aversion. Journal of Pharmacology and Experimental Therapeutics, 269: 137-144.

26. Suzuki T, Otani K, Koike Y \& Misawa M (1988). Genetic differences in preferences for morphine and codeine in Lewis and Fischer 344 inbred rat strains. Japanese Journal of Pharmacology, 47: 425-431.

27. Suzuki T, George FR \& Meisch RA (1988). Differential establishment and maintenance of oral ethanol reinforced behavior in Lewis and Fischer 344 inbred rat strains. Journal of Pharmacology and Experimental Therapeutics, 245: 164-170.

28. Khanna JM, Kalant H, Chau AK \& Sharma H (1990). Initial sensitivity, acute tolerance and alcohol consumption in four inbred strains of rats. Psychopharmacology, 101: 390-395.

29. Wood WG, Elias MF \& Pentz CA (1978). Ethanol consumption in genetically selected hypertensive and hypotensive mice. Journal of Studies on Alcohol, 39: 820-827

30. Goodwin FLW \& Amit Z (2000). Relative taste thresholds for ethanol, saccharin, and quinine solutions in three strains of rats nonselected for ethanol: a comparative study. Experimental and Clinical Psychopharmacology, 8: 216-224.

31. Terenina-Rigaldie E, Jones BC \& Mormède P (2003). Pleiotropic effect of a locus on chromosome 4 influencing alcohol drinking and emotional reactivity in rats. Genes, Brain and Behavior, 2: 125-131.

32. Wittchem HU, Zhao S, Kessler RC \& Eaton WW (1994). DSM-III-R generalized anxiety disorder in the National Comorbidity Survey. Archives of General Psychiatry, 51: 355-364. 